\title{
A Review on Marginal Deterioration of Composite Restoration
}

\author{
Priyalakshmi.S ${ }^{1}$, Manish Ranjan ${ }^{2}$ \\ ${ }^{1}$ Under graduate student Department of conservative dentistry, Saveetha Dental College, India \\ ${ }^{2}$ Reader Department of conservative dentistry, Saveetha Dental College, India
}

\begin{abstract}
Dental treatment procedures are increasingly governed by factors such as biocompatibility of restorative materials, patients demands for esthetics and a conservative approach to minimize loss of tooth structure.G.V Black was the first person to describe the ideal cavity form to restore carious lesions. G.V Black followed "EXTENTION FOR PREVENTION" as ideal principle for cavity preparation.Such classical cavity forms and principles remained appropriate and largely unchallenged for a period of 50 years using Amalgam However amalgam cavities require uniform depth, particular wall forms with excessive tooth damage to ensure retention of amalgam. So patients demand for tooth coloured restoration, with minimal sacrifice of sound tooth structure was increased and it depends mainly on adhesion of the restorative material that provide strong and durable bonding to the remaining sound enamel and dentin. This led to the introduction of aesthetic restorative material known as Composite Resins which has taken dentistry a step closer to the goal.Dental composites are highly cross linked polymeric materials reinforced by a dispersion of glass, crystalline, or resin filler particles and short fibers bound to the matrix by silane coupling agents. The predictors of marginal deterioration has been reviewed in this article.
\end{abstract}

\section{Introduction}

An ideal restorative material must not only establish effective seal between the restoration and the tooth but also should strengthen the tooth and maintain aesthetics. Despite the improvement of many restorative materials themarginal integrity of the restoration remains a challenge for dentistry. The marginal integrity of composite restoration refers to its marginal fit and marginal adaptation thereby increasing the longitivity of the restorative material. The marginal deterioration refers to poor marginal adaptation which may produce marginal discoloration, post operative sensitivity and secondary caries. These are the most frequent reasons to replace or repair an adhesive restoration. The marginal failure of composite resin restoration is related mainly to the quality of bonding to the dental structures and the stress generated on the restoration [1] When the resin composite is bonded to tooth structure using adhesives the initial and residual polimerization stresses that are present along the cavity walls results in gap formation, micro leakage which leads to recurrent caries and pulpal irritation [2] The detrimental effect of marginal gap formation cannot be offset even with the use of flouride releasing adhesives or restorative material that prevent the demineralization along cavity margins[3] Thus only hermetic sealing of restorations guarantees clinical success [4] The accurate evaluations of margin qualities are important for identification of the risk of future failure of composite restorations. The clinical evaluation of marginal deterioration can be done using modified USPHS criteria which includes evaluation of marginal adaptation, marginal discolouration, secondary caries. The loss of marginal adaptation and the presence of secondary caries are predictors of the failure of composite resin restorations and being the main reason for the replacement of restorations [5] Marginal fit is assumed to affect the restoration longevity by either encouraging or discouraging microleakage and development of secondary or marginal caries.[6]

II. Modified USPHS Evaluation Criteria[7]

\begin{tabular}{|lc|}
\hline Marginal Discoloration & Alfa:No Discoloration \\
\hline & Bravo:Acceptable mismatch \\
\hline Charlie:Unacceptable mismatch \\
\hline Marginal Adaptation & \\
\hline & Alfa:Closely adapted, no visible crevice \\
\hline & Bravo:Visible crevice,explorer will penetrate \\
\hline Charlie:Crevice in which dentin is exposed \\
\hline Secondary Caries & Alfa:No caries present \\
\hline & Charlie:caries present \\
\hline
\end{tabular}




\section{MARGINAL ADAPTATION[3.1]}

\section{Predictors Of Marginal Deterioration}

The dental explorer has been used for the diagnosis of caries and for marginal evaluation. A proper marginal sealing is essential to improve the longitivity of composite resin restoration [8][9][10]Marginal adaptation in composite restorations is related to some factors like type of dentin adhesive, restoration technique, band accuracy in finishing restoration.[[11]] The most of the clinical studies evaluating the performance of an adhesive system considers the $\mathrm{C}$-factor . The $\mathrm{C}$-factor of the cavities impairs the composite resin flowing during the polymerization shrinkage, increasing the stress over the bonding interface [12][13]Composite restoration ,stresses submitted on the restoration can disrupt the bonding and lead to the formation of gaps. Thus the proper bond of an adhesive to the dental tissue contributes to avoid marginal microleakage. [14] [15] Bonding to enamel is predictable and stable because of the substrates high mineral content. [16]In contrast with the enamel, dentin is a more heterogeneous substrates, consisting of hydroxyatite , collagen fibrils and water. The acid conditioning of the dentin widens the opening of the dentinal tubules exposes a layer of mineral depleted collagen fibrils and increases water content.[17]The presence of the organic content and water impairs proper bonding. The presence of solvents and hydrophilic components in the adhesive layer of the self etching adhesive can compromise the adhesives proper polymerization.[18][19].On the other hand the ClearfilSE bond presents a hydrophilic adhesive that is applied on the etched dentin by a self etching primer. This explains the lowest gaps observed in the margins of the dentin when the Clearfil SE is used when compared to self etching adhesive.[20][21]Thus the more stable bonding to the dental substrate contributes to maintain margin sealing. Moreover $60 \%$ of marginal fractures have been found in cavity preparations which has widths of more than two third of intercuspal distance.[22]

\section{SHRINKAGE AS THE PREDICTOR OF MARGINAL DETERIORATION.[3.2]}

POLYMERIZATION Composite restorations are subjected to polymerization shrinkage which occurs due to affiliation of the resin molecules with one another and formation of chemical bonds which reduce the material sbulk[23]The $\mathrm{C}$-factor plays an major role in determining the amount of shrinkage. $\mathrm{C}$ factor is defined as the ratio between the bonded and unbounded cavity surfaces. Increasing this ratio also increases the stress from polymerization shrinkage.[24]Shrinkage of composites results in stresses, cuspal deflection which inturn leads to enamel cracks, hypersensitivity, marginal degradation, microleakage. It also includes potential debonding of the tooth composite interface.[25]The amount of shrinkage and stresses varies with the composite filling material used.[26][27].It is influenced by material flow, chemistry, curing dynamics and the size and shape of the preparation, hygroscopic expansion. The intensity and duration of curing have been found to affect polymerization.[28] Polmerization shrinkage stress of composite resin is about 13-17MPa.Therefore adhesive agents should have a good bond strength higher than this amount.[29][30]Polymerization shrinkage of composites can lead to microleakage which can cause an immediate inflammatory reaction in pulp.[31][32][33]. Three different strategies to reduce polymerization stress includes modification to placement technique, altered curing schemes, use of a resilient liner on dentin.[34][35]

\section{MICROLEAKAGE[3.3]}

When composite resin is placed on dentin or cementum,a high potential exists for marginal gap formation.[36]This gap predisposes the restorative margin to microleakage, secondary caries and marginal discolouration.[37][38]Marginal leakage can be defined as the passage of fluids, bacteria or molecules between a cavity wall and the restorative material because of the presence of micrometric spaces.[39]Marginal leakage is a cause of failure of composite resin restorations as a result of lack of the lack of adhesion, which is responsible for marginal discolouration.[40]Marginal staining is mentioned as a clinical sign of microleakage.[41][42].Major reported that the relatively high proportion of marginal discolouration suggests inadequate acid-etching of the enamel prior to placing the resin-based composite restorations and or inadequate fabrication of the restoration in addition to the inherent problems associated with polymerization shrinkage. The increase in etched surface area results in stronger enamel to resin bond, which increases the retention of the restoration and reduces marginal leakage and marginal discolouration.[43][44].The marginal staining of the restoration also depends on proper shade selection, finish of the margins of restorations and oral hygiene of the patient.

\section{SECONDARY CARIES[3.4]}

Secondary caries has been consistently found to be the most common reason for replacement of restorations. It is also known as marginal caries which refers to the carious lesions found adjacent to existing restoration margin.[45]The high incidence of secondary caries associated with the resin composite restorations may be explained on the basis of microbiological findings.[46]Secondary caries is thought to be associated with marginal gaps, voids and openings along the margins of existing restoration. A significantly higher proportion of 
streptococcus mutans was found at the cavity margins of the resin composite restorations than for the other materials.[47]Recurrent caries may arise from remnants of infected dentine, incompletely removed during cavity preparation or more commonly from oral microorganisms which gain entry via leaky filling margin. All composites shrink during curing. It is important to minimize the effect of composite shrinkage by incrementally placing and curing materials.[48]

\section{Silorane-Based Posterior Restorations.}

Silorane is derived from combination of siloxane and oxirane and has compact ring structure that unlinks during polymerization.It reduces polymerization shrinkage and associated stresses, which would also reduce microleakage and postoperative sensitivity while demonstrating other physical properties comparable to leading composites.[49]

\section{Conclusion}

Increasingly composite are being placed in preference due to patient demands for esthetics as well as the clinical desire to do minimal preparation where possible and provide patients with bonded esthetic restorations.However composite restorations fails mainly due to polymerization shrinkage.Further investigations are required at reducing polymerization shrinkage to increase the longitivity of restoration and reduce the potential for failure.

\section{References}

[1] Rodrigues SA Jr, Pin LF Machado G, Della Bona A, et al Influence of different restorative techniques on the marginal seal of class II composite restorations J Appl Oral Sci 2010.18:37-43

[2] Fabianelli A, kugel G, Ferrari N Efficiency of self-etching primer on sealing margins of class II restorations Am J Dent 2003. 16:37-41

[3] Savarino L, Saponara Teutonico A, Tarabusi C, et al Enamel microhardness after in vitro demineralization and role of different restorative materials J Biomater Sci Polym Ed 2002.13:349-357

[4] Tay FR, pashley DH, Suh BI, et al Single step adhesives are permeable membranes J Dent 2002.30:371-382

[5] Letzel H, Survival rates and reasons for failure of posterior composite restorations in multicentre clinical trial J Dent 1989.17 Suppl 1:S10-17

[6] Thomas D Larson , D.D.S., The clinical Significance of Marginal Fit February 2012.Vol:22-29

[7] Cigdem Celik,Neslihan,Kivanc Yamanel Clinical Evaluation of Resin-Based Composites in Posterior Restorations 12-Month Results January 2010.Vol 4:57-64

[8] Ekguzeloglu Dalkilic E, Omurlu H, Two -year clinical evaluation of three Adhesive systems in non-carious cervical lesions.J Appl Oral Sci.2012.20:192-9

[9] $\mathrm{H}$ eintze SD, Systemic reviews : 1.The correlation between laboratory tests on marginal quality and bond strength .II.The correlation between marginal quality and clinical outcome.J Adhes Dent. 2007.9:77-106

[10] Rodrigues SA Jr, Pin LF Machado G, Della Bona A, et al Influence of different restorative techniques on the marginal seal of class II composite restorations J Appl Oral Sci 2010.18:37-43

[12] Ekguzeloglu Dalkilic E, Omurlu H, Two -year clinical evaluation of three Adhesive systems in non-carious cervical lesions.J Appl Oral Sci.2012.20:192-9

[13] Santiago SL, Passos VF, Viera AH, et al Two year clinical performance of resinous restorative system in non-carious cervical lesions Dent J, 2010.21:229-34

[14] De Munck J, Van L anduyt K, Peumans M,et al A critical review of the durability of adhesion to tooth tissue:methods and results J Dent Res .2005.84:118-32

[15] Kenshima S, Grande RH, Singer JM et al Effect of thermal cycling and filling technique on leakage of composite resin restorations.J Appl Oral Sci . 2004.12:307-11

[16] Sliva e souza aMH Jr, Carneiro KG, Lobato MF, Adhesive systems: Important aspects related to their composition and clinical u se. J Appl Oral Sci.2010.18:207-14

[17] Sliva e souza aMH Jr, Carneiro KG, Lobato MF, Adhesive systems: Important aspects related to their composition and clinical use. J Appl Oral Sci.2010.18:207-14

[18] Cadenaro M, Breschi L, Ruggeberg FA,el al Effects of residual ethanol on the rate and degree of conversion of fiver experimental resin . Dent Mater .2009.25:621-8

[19] Faria-e-Sliva AL, Lima AF, Moraes RR, Degree of conversion of etch- and-rinse and self-etch adhesives light-cured using QTH or LED. Oper Dent 2010.35:649-54

[20] Andrade e sliva Sm, Carrilho MR, Marquexini Junior, et al Effect of an additional hydrophilic versus hydrophobic coat in the quality of dentinal sealing provided by two step etch -and -rinse adhesives. J Appl Oral Sci.2009.17:184-9

[21] Reis A, Giannini M, Kavaguchi A, Improving clinical retention of one-step self etchng adhesive system with an additional hydrophobic adhesive layer. J Am Dent Assoc .2009.140:877-85

[22] F ukushima M, Setcos JC, Ralph WP, Marginal fracture of posterior composite resins. J Am Dent Assoc 1998.117:577-83

[23] Gonzailez-Lopez \& , Vilchez Diaz MA, de Haro-Gasquet F, et al Cuspal flexure of teeth with composite restorations subjected to occlusal loading Adhes Dent .2007 Feb .9(1):11-5

[24] Feilzer AJ, de Gee AJ, \&Davidson CL(1987) Setting stress in composite resin in relation to configuration of the restoration Journal of Dental Research 66(11) 1636-1639.

[25] Van Dijken JW. A 6-year clinical evaluation of Class I poly acid modified resin composite/resin composite laminate restorations cured with a two-step curing technique . Dent Mater .2003.19(5):423-8

[26] Rutteermann S, Kruger S, Raab WH, et al Polymerization shrinkage and hygroscopic expansion of contemporary posterior resin based filling materials a comparative study J Dent 2007.35(100:806-13 Epub 2007 Sep 10

[27] Cadenaro M, Biasotto M, Scuor N, et al Assessment of polymerization contraction stress of three composite resins . Dent Mater 2008.24(5):681-5Epub 2007 Aug 31 
[28] Visvanathan A, Ilie N, Hickel R, et al The influence of curing times and light curing methods on the polymerization shrinkage stress of a shrinkage -optimized composite with Hybrid -type prepolymer fillers. Dent Mater 2008.23(7):777-84, Epub 2006 Aug 17

[29] De Gee AJ, Feilzer AJ , Davidson CL. True linear polymerization shrinkage of unflled resins and composites determined with a linometer, Dent Mater 1993;9:11-4

[30] Mandras RS, Thurmond JW, Latta MA et al Three year clinical evaluations of the clearfil Liner Bond. Oper Dent 1997.22:266-70

[31] Swift EG. Pulpal effects on composite resin restoration. Oper Dent 1989.14:20-7

[32] Suzuki M, Jordan RE, Boksman L. Posterior composite Resin Restoration . Clinical Consideration . Posterior Composite Proceeding of the International on Posterior Resins 1985.455-64

[33] Van Meerbeek B, Vargas M, Inoue S et al Adhesives and cements to promote preservation dentistry Oper Dent 2001.Suppl 6,11944

[34] Ferracane JL (2008) Buonocore Lecture . Placing dental composites -A stressful experience Operative Dentistry 33(3) 247-257

[35] Deliperi S, 7 Bardwell DN (2002) An alternative method to reduce polymerization shrinkage in direct posterior composite restorations Journal of the American Dental Association 133(10) 1387-1398

[36] Barnes DM, Thompson VP, Blank LW. Microleakage of class V composite resin restorations a comparison between in vivo and vitro . Oper Dent $1993 ; 18: 237-245$

[37] Barnes DM, Thompson VP, Blank LW. Microleakage of class V composite resin restorations a comparison between in vivo and vitro . Oper Dent $1993 ; 18: 237-245$

[38] Loiselle RJ, Goldberg AF, Gross RL . Marginal microleakage an in vivo assessment . J of the Am Dent Asso 1969; 78:758-760

[39] Weinmann W, Thalacker C, Guggenberg R. Silorances in dental composites Dent Mater , 2005;21(1):68-74

[40] Relief DH. Clinical applications of enamel adhesives . Oper Dent 1992; Supplement 5;44-49sss[41]Aw TC , Lepe X, Johonson GH, A three-year clinical evaluation of two -bottle versus one-bottle dentin adhesives . J Am Dent Assoc . 2005; 136(3):311-22

[42] Kidd EAM . Microleakage :a review .J Dent .1976;5(4):199-206

[43] Ibsen RL and Neville K . Adhesive restorative dentistry . Philadelphia W.B Saunders Co, 1974

[44] Well D.A and Laswell HR. Rationale for designing cavity preparations in light of current knowledge and technology . Dent Clin North Am 1976;20(2):231

[45] Mjor IA, The reasons for replacement and the age of failed restorations In general practice.Acta Odontol Scand . 1997 Jan;55(1):58-63

[46] Svanberg M, Mjor IA and Qrstavik D. Mutans streptococci in plaque from margins of amalgam, composite and glass ionomer restorations. J Dent Res 1990;69:861-864

[47] Mjor IA, and jokstad A Five-year study of class II restorations in permanent teeth using amalgam , glass polyalkenoate (ionomer) cermet and resin-based composite materials . J Dent 1993;21:338-343

[48] Bayne SC , Heymann HO and swift Ejjr . Update on dental composite restorations . JADA1994; Vol.125,6:687-701

[49] Ilien Hickel R.Silorane-based dental composite:behavior and abilities.Dent Mater J.2006;259(3):445-454. 